Renato Cristi, El pensamiento político de Jaime Guzmán. Una biografía intelectual (Santiago: Lom Ediciones, 2011) segunda edición.

\title{
JAIME GUZMÁN: UNA ODISEA POLÍTICO-RACIONAL
}

\section{Belén Moncada Durruti}

Resulta llamativo que existan en Chile tan pocos libros dedicados al examen y análisis del pensamiento de uno de los políticos más controvertidos e influyentes de su historia reciente. Guzmán es hoy, sin duda, referente ideológico y político de primer orden, y su acción y pensamiento sobrevuelan, se quiera o no, el entramado institucional chileno de hoy en día. Por eso no es en absoluto sorprendente que vea la luz una segunda edición de la mejor biografía intelectual que se ha hecho sobre Jaime Guzmán. El libro de Renato Cristi El pensamiento político de Jaime Guzmán constituye un referente básico para entender los orígenes ideológicos de la construcción política del Chile actual.

El objetivo del libro es analizar la obra y elaborar una exposición crítica del pensamiento de Guzmán, con las nociones de autoridad y libertad como encuadre general. La segunda edición de esta obra (la primera fue publicada en el año 2000) aporta lo que consideramos que es un gran acierto: hacer un esfuerzo por contextualizar aún más el pensamiento de Guzmán. Una contextualización que, a ojos de los historiadores, nunca será suficiente. Con este ánimo, Cristi analiza de nuevo la trayectoria del senador, descubriendo el tejido filosófico que subyace

Belén Moncada. Doctora en Historia. Directora de Estudios del Instituto Empresa y Humanismo de la Universidad de Navarra (bmoncada@ unav.es; belmoncada@yahoo.com). Autora, entre otras publicaciones, del libro Jaime Guzmán el político: Una democracia contrarrevolucionaria (Ril Editores, 2006).

Estudios Públicos, 125 (verano 2012). 
detrás de cada uno de sus planteamientos políticos. El autor explica de modo pormenorizado cómo evolucionan las posturas de Guzmán, las corrientes ideológicas a las que responden, y los conceptos filosóficos que defiende a lo largo de su vida política.

En este riguroso examen del pensamiento de Guzmán, Cristi acota doctrinalmente la visión del gremialista sobre el Estado, la libertad, Constitución, economía, derechos humanos y legitimidad. Demuestra cómo el político consigue concebir un Estado autoritario y una sociedad libre, acomodando la democracia dentro de un conservadurismo liberal por medio del concepto hayekiano de democracia instrumental. El autor incluye aquí un apéndice sobre el pensamiento de Hayek, también presente en la primera edición. En él se centra sobre todo en los aspectos que hacen relación a su definición de libertad y democracia. Si bien el texto tiene gran interés a la hora de constatar las similitudes entre los conceptos de libertad y democracia instrumental hayekianos que el autor detecta en Guzmán, quizá su inclusión en el libro resulta algo excesiva. Con todo lo interesante que resulta para comprender mejor el pensamiento del liberal, el apéndice es más valioso como explicación de los principios republicanos a los que adscribe Cristi.

Cristi examina la fundamentación metafísica y explica cómo Guzmán defiende desde un principio el capitalismo, incluso desde sus primeras posturas corporativistas. Su idea de Constitución es examinada en el tercer capítulo, donde el autor incluye las Actas de la Junta de Gobierno que hacen referencia al papel de Guzmán en la destrucción de la Constitución de 1925 y la génesis de la del 80. Analiza también su concepto de democracia y las tesis sobre liberalismo económico.

En mi opinión, para sacar el máximo provecho del libro de Renato Cristi, sería conveniente leer primero los dos últimos capítulos. El autor utiliza las últimas páginas de su libro para explayarse sobre la democracia republicana y las concepciones de autoridad y libertad que de ella se derivan. Esta es, en definitiva, la posición del propio Cristi. Una vez que el lector entienda el criterio filosófico-político del autor, estará en condiciones mucho mejores de abordar la relectura que él hace de Guzmán, y entender las críticas a su planteamiento. Tras estos dos capítulos, de alguna manera se entiende que la figura de Guzmán pueda ser enormemente atrayente para el republicanismo. Las tradiciones filosóficas de las que bebe el político, sus guiños corporativistas y su concepto de autoridad evocan en la lejanía y hasta cierto punto la posición de un republicano que no pudo ser. 
Renato Cristi responde en esta segunda edición a alguna de las críticas que se le hicieron a la primera que, en definitiva, pueden resumirse en una única cuestión: ¿Es Guzmán un ideólogo, un filósofo de la ciencia política — que, por tanto, amerita un rastreo académico de su pensar y actuar-, o es por el contrario un político, y como tal sujeto a la contingencia de lo práctico? Ya en la introducción de su libro, Cristi rebate (lo hará de mil modos a lo largo de los capítulos), aquello que se le achaca. No cabe otra respuesta: "su pragmatismo dificulta la reflexión acerca de sus propios fundamentos filosóficos"1.

\section{El sistema económico y el peso del contexto}

El autor demuestra a lo largo de su obra que la defensa del capitalismo es uno de los elementos que determinan la continuidad de la obra de Guzmán. Cristi rastrea las corrientes y concepciones filosóficas hasta demostrar que su concepto de libertad no es republicano sino liberal ${ }^{2}$. Sin duda, más allá de los fundamentos ideológicos, gran parte de la explicación de esta defensa a ultranza del capitalismo debe buscarse también en las circunstancias y el tiempo histórico que a Jaime Guzmán le tocó vivir. Cristi es consciente de ello, y en esta edición procura contextualizar el pensamiento y los escritos de Guzmán con el fin de comprender mejor su pensamiento. Señala cómo en su juventud Guzmán se pliega a las corrientes contrarrevolucionarias propias del tradicionalismo español en contra de la "reforma del macetero" de Alessandri. Desde ese punto y hasta la declarada estatización de la propiedad por parte de Allende, Guzmán siente que la propiedad privada está siendo amenazada. Por ello, buscará en el bagaje intelectual del conservadurismo chileno los argumentos que en cada momento mejor le sirvan para defender este principio. Serán las ideas carlistas en su etapa juvenil, el movimiento gremialista en su etapa universitaria, y el derecho a la rebelión fundado en la ilegitimidad de ejercicio durante el gobierno de Allende ${ }^{3}$. Todo ello lo describe magistralmente Cristi en el capítulo 7, que añade a esta edición. En este mismo capítulo Cristi hace un sugestivo recorrido por la teoría carlista, deteniéndose en su recep-

${ }^{1}$ Renato Cristi, El pensamiento politico de Jaime Guzmán: Una biografia intelectual, 2011, p. 74.

2 Ibíd., p. 52.

${ }^{3}$ Ibíd., pp. 203 y ss. 
ción en Chile de la mano de Osvaldo Lira. De la lectura que Guzmán hará de ella se deduce la justificación que más tarde utilizará a favor del golpe de Estado de 1973: la legitimidad de ejercicio, la diferencia entre nación — sustrato orgánico y espiritual—y Estado —-formulación jurídica de ésta-, y la defensa que de aquélla deben las Fuerzas Armadas como garantes de la institucionalidad.

Por otro lado, Guzmán es indudablemente hijo de la guerra fría, al igual que el pensamiento económico neoliberal que termina adscribiendo; le resulta imposible asumir la posible existencia de una tercera vía entre capitalismo y socialismo. Tal y como señala Cristi, Guzmán intenta defender la economía capitalista desde los primeros momentos de su acción política. Amparándose en una lectura sesgada de la Encíclica Mater et Magistra, el senador defiende una economía capitalista, "pero no una sociedad capitalista"4. En nuestra opinión, esto es posible solo en el papel, ya que en la práctica resulta inasumible e ingenuo no reparar en ello. En la medida en que el enriquecimiento de un país depende de lo que venda, es necesario "educar" a la población en una actitud consumista. Por ello la economía capitalista genera constantemente nuevas necesidades, lo que termina creando, de modo casi automático, un determinado tipo de sociedad a la que comúnmente llamamos capitalista o consumista ${ }^{5}$. El juego de mercado como política económica lleva consigo en alta medida la pleonexia, por lo que resulta ingenuo no reparar en su conexión con el capitalismo. Esa "sociedad" capitalista es la que rechaza Guzmán, sin darse cuenta quizá, que se origina casi automáticamente con la economía de mercado.

En el capítulo sobre Catolicismo y Capitalismo, Cristi añade en esta nueva edición un apartado sobre la tesis de Universidad de Guzmán. En él Cristi encuentra una conexión entre el concepto de

${ }^{4}$ Cfr. Jaime Guzmán, "El capitalismo y los católicos de tercera posición", Fiducia, 1965, p. 5. También en "La Iglesia chilena y el debate político", recogido por Arturo Fontaine Talavera en "El miedo y otros escritos: El pensamiento de Jaime Guzmán E.”, Estudios Públicos, 1991, p. 279.

5 Siguiendo a Pérez Adán, "como consecuencia, no sólo se toleran sino que se esperan y fomentan actitudes consumistas en el marco de programas de austeridad económica". José Pérez Adán, "Pautas de evaluación para el desarrollo y la igualdad en América Latina”, en XIII Congreso Iberoamericano Ciencia y Vida: Dignidad e Igualdad en América Latina, 2007. Estos comentarios son recogidos en parte en mi artículo "Financiación de la cohesión social: consideraciones e inquietudes", 2008, pp. 365-370. 
sociedad que define el entonces universitario con el que más tarde casará con la economía neoliberal. Según Cristi, Guzmán consideraba la sociedad como un ser accidental, frente al individuo que define como ser sustancial. De este modo, Guzmán "despoja” a la sociedad de su carácter necesario, lo que dejaría en entredicho la naturaleza social del hombre, elevando por encima de ésta el derecho inalienable de la propiedad privada. Para Cristi, esta concepción guzmaniana de sociedad se acerca "peligrosamente" al nominalismo de Ockham y lo aleja de Santo Tomás. Cristi lo explica aduciendo que Guzmán no diferencia, como sí lo hace Santo Tomás, entre accidentes necesarios y accidentes contingentes 6 .

En este punto nos cuesta coincidir con Cristi. En nuestra opinión, es forzado colegir la negación de la naturaleza social del hombre por la afirmación de su prioridad ontológica sobre el Estado o la sociedad. Al fin y al cabo, Guzmán no define qué tipo de accidente es la sociedad. Por lo tanto, bien puede pensarse que lo consideraba accidente necesario. En ese caso, no estaría anulando la naturaleza social del hombre, sino solamente estableciendo la prioridad ontológica de éste sobre la sociedad. Esa prioridad no elimina la necesidad del sujeto de perfeccionarse en sociedad, aunque ésta sea considerada un accidente. Aquí Cristi se decanta por otorgar a Guzmán el carácter más liberal posible, sin llegar a demostrarlo plenamente.

No hay que olvidar, en cualquier caso, que con frecuencia las ideas que defiende Guzmán en política no van unidas a lo que se desprende de sus trabajos académicos, como puede ser su trabajo de fin de grado. Esta realidad solo puede entenderse si se asume que el compromiso de Guzmán con cualquier principio está basado en un interés político, en su posibilidad práctica, no filosófica. De ahí que el mismo Cristi reconozca, como decíamos al principio, que su realismo pragmático dificulta la reflexión sobre la fundamentación de Guzmán.

\section{Democracia instrumental frente a democracia republicana}

Uno de los aspectos más interesantes del pensamiento de Guzmán y que Cristi estudia con detenimiento, es el que hace referencia a sus conceptos de constitucionalismo y democracia. Su designación para

${ }^{6}$ Renato Cristi, El pensamiento politico de Jaime Guzmán: Una biografia intelectual, 2011, pp. 87-88. 
dirigir el estudio de una nueva Constitución se revela en la primera Acta de la Junta de Gobierno del 13 de septiembre de 1973 que recoge el libro. Su capítulo sobre la influencia de Schmitt en la concepción constitucional de Guzmán es muy revelador en este sentido: en opinión de Cristi, la decisión promulgada por el Decreto Ley 1 de gestar una nueva Constitución por parte de la Junta Militar supone la instauración de una dictadura "soberana" - y no meramente comisaria - sin limitaciones institucionales, tal y como entendía el alemán la soberanía absoluta del Poder Constituyente. El matiz no es menor, ya que desde el punto de vista jurídico, crear una nueva Constitución implica la derogación automática de la Constitución de 1925 y supone la aceptación de que la Junta es depositaria del poder constituyente originario, y no el pueblo chileno ${ }^{7}$.

Respecto al concepto guzmaniano de democracia, Cristi demuestra cómo el senador se adhiere a una idea de democracia entendida como forma instrumental de gobierno, que regule las opciones políticas de los ciudadanos. Pero ese instrumento democrático no puede nunca amenazar la forma de vida que se considera adecuada. De ahí que Guzmán entienda la Constitución como el establecimiento de una autoridad fuerte, casi monárquica — dirá Cristi- que pueda limitar la democracia y salvaguardar siempre la libertad individual. Para el autor, por tanto, el empeño constitucionalista de Guzmán respondería más a una lógica de defensa de la libertad económica que a una lógica de defensa "doctrinal".

Personalmente nos inclinamos a pensar que su constitucionalismo manifiesta más bien el interés por salvaguardar su visión de

${ }^{7}$ Renato Cristi, "La noción de poder constituyente en Carl Schmitt y la génesis de la Constitución chilena de 1980", 1993, pp. 229-250. Respecto a la promulgación de este decreto, Claudio Orrego, intelectual de la Democracia Cristiana y amigo de Guzmán, escribía a éste en una carta personal comentarios que nos parecen muy significativos de la percepción que se tuvo de este decreto: "La aparición del nuevo decreto aclaratorio de las 'funciones constituyentes y legislativas' es ya la muerte oficial del Estado de Derecho. No vamos a decir que vivíamos en el reino de la juridicidad, pero nunca se pensó que pudiéramos llegar al extremo de que la Constitución y la Ley pasan a confeccionarse a la medida de las necesidades políticas y represivas de la autoridad administrativa. Es de verlo y no creerlo. Sobre todo después de haber dado tan larga y noble lucha en contra de los resquicios legales" (Claudio Orrego Vicuña, Cartas privadas: 1973-1977, 2002), pp. 163-164. 
democracia ante otras posibles en un Estado doctrinalmente neutral. Constituye más una crítica a un posible control ideológico adverso que al estatal-económico (aunque ambos van indefectiblemente unidos). Así quedaría demostrado en el empeño que puso en plasmar en el Artículo $\mathrm{N}^{\mathrm{o}} 2$ de la Constitución y no en el preámbulo la definición de bien común ${ }^{8}$. Guzmán insiste mucho en este punto, al considerar que es precisamente la indefinición del concepto de bien común lo que posibilitó su distorsión por los distintos gobiernos. Definiendo el bien común de manera clara e inequívoca, quedaría también definido el Estado y su finalidad, acabando así con la neutralidad ideológica que el Estado liberal asume y que, en opinión de Guzmán, es lo que provoca un pluralismo ideológico ilimitado e irrestricto que conduce a la acción totalitaria ${ }^{9}$. A juicio de Guzmán, al establecer claramente qué se entiende por bien común, el Estado queda definido ideológicamente, evitando así su posible malinterpretación.

Parece que el objetivo de la nueva Constitución era, por tanto, definir ideológicamente el Estado para que no cupieran en él interpretaciones totalitarias o contrarias a la chilenidad. Era necesario para el comisionado concretar todo lo posible el fin del Estado. El único problema de esta pasión por definir ideológicamente el bien común es que queda fuera todo lo que encerraba su agradable ambigüedad. Así se lo hicieron ver otros comisionados, y críticas como las de Díez ${ }^{10}$.

Es interesante ver cómo, según lo definió el gremialista, el Estado no tiene la obligación de crear las condiciones sociales que permitan alcanzar la plena realización, sino que su obligación es la de promoverlas. El problema, a nuestro juicio, está en saber hasta dónde el Estado está obligado en esa "promoción" y en ese "favorecer". ¿Hasta qué punto se favorece la participación social? ¿Cuánto o hasta dónde se promueve? ¿Desde qué criterios actúa el Estado para hacer respetar los derechos inalienables de los individuos? Desde nuestro punto de vista, la distinción es clave, y supone un grado de obligatoriedad por parte del Estado completamente distinto en uno y otro caso ${ }^{11}$. Ésta es la cuestión que planea

8 “Actas Oficiales de la Comisión Constituyente", Sesión 37, pp. 9 y 10.

${ }^{9}$ Cfr. Belén Moncada Durruti, Jaime Guzmán el político: Una democracia contrarrevolucionaria, 2006, pp. 196 y ss.

10 "Actas Oficiales de la Comisión Constituyente", Sesión 45, 13 de junio de 1974, p. 15. pp. 200-201.

${ }^{11}$ Cfr. Belén Moncada Durruti, Jaime Guzmán el político..., 2006, 
sobre las críticas de Díez a Guzmán, y de algún modo, también sobre las de Cristi: en una definición de Estado "no neutral" ideológicamente puede ir implícita la defensa de éste a la libertad económica.

\section{La mirada sobre Guzmán}

Mirar a Guzmán con ojos de filósofo, como lo hace Cristi, puede considerarse la perspectiva más adecuada para valorar su legado. El análisis que de la figura del político hace el autor marca la distancia necesaria para evitar el excesivo apasionamiento que, con frecuencia, aflora en la valoración política o moral de su persona. Por ello, coincidimos con el autor en que el análisis filosófico es la principal herramienta para comprender la obra de Guzmán. No obstante, adoptar exclusivamente la perspectiva académica no resulta del todo acertado para evaluar su legado práctico. Indagar en la trayectoria filosófica de quien perseguía utilidad política, indefectiblemente llevará consigo la aparición de contradicciones. El peso del "contexto" en el análisis de Guzmán es absolutamente decisivo.

¿Es Guzmán, entonces, un político carente de principios? De ningún modo. Cristi demuestra con el mayor acierto que el pensamiento de Guzmán constituye una asimilación de las corrientes filosóficas chilenas: por un lado, el pensamiento conservador chileno en sus vertientes nacionalista y corporativista, y por otro la economía liberal que llega a Chile fundamentalmente de manos de los alumnos de la Escuela de Chicago. La cuestión está en que no resulta tan "demostrable" que todo ello constituya una unidad de pensamiento, una síntesis genial de distintos programas filosóficos. Más bien demuestra el esfuerzo de convertir en practicables políticamente unos conceptos que hasta un determinado momento fueron opciones intelectuales. Este interés guzmaniano de conjugar la practicidad de un ideal es, desde nuestro punto de vista, el rasgo más característico de su personalidad política"12.

El intento de casar las diferentes posturas político-filosóficas de Guzmán con una determinada teoría doctrinaria es arriesgado, ya que Guzmán ante todo fue un político, y si por algo se caracterizaba su pensamiento era por su adecuación a la realidad posible, su aplicabi-

${ }^{12}$ Belén Moncada Durruti, Jaime Guzmán el político..., 2006, p. 195. 
lidad por encima de cualquier teoría o escuela. Su génesis intelectual, así como su evolución política, estuvieron demasiado determinadas por las circunstancias históricas. En este sentido -y aquí disentimos de Cristi-, el pensamiento de Guzmán no puede verse en el marco de una evolución intelectual dentro de distintas corrientes de pensamiento, sino más bien como sucesivos intentos de llevar a la práctica un ideal que se iría perfilando en virtud del sentido de la oportunidad. Por eso, de cada escuela toma lo que más le conviene en cada momento ${ }^{13}$.

Por ello a Guzmán cabe mirarlo únicamente con ojos, ni siquiera de político, sino únicamente de historiador. De otro modo, en función del momento, podríamos encontrar que Guzmán sería conservador, liberal, republicano, nacionalista, demócrata y autoritario.

\section{El racionalismo de Guzmán}

A mi juicio, la cuestión no está en si Guzmán es más pensador que político, o más político que pensador. La clave está en que es una persona excesivamente "racionalista", rasgo muy acusado de su carácter, que tiene sus consecuencias en su actuación política. Tal y como lo describe su hermana se entiende perfectamente:

En cuanto a su manía racionalizadora, debo decir que a veces alcanzaba ribetes de broma. A él le parecía necesario blandir una explicación para cada uno de sus actos. Nada en él era fruto del azar o la espontaneidad: siempre había un por qué elegir esa habitación en vez de la del lado en el lugar donde veraneaba... o por qué la sopa debiera ser de espárrago y no de choclo... o por qué las comidas tenían que ser de un máximo de ocho personas... o por qué era preferible andar en bus que en taxi...14.

No obstante, resulta difícil no considerar a Guzmán como un teórico sistemático ya que, movido quizás por un prurito racional, es el propio gremialista quien se empeña en justificar posturas políticas más allá de lo conveniente: no puede dejar cabo suelto, no hay nada que

${ }^{13}$ Cfr. mi crítica a la primera edición de la obra de Cristi en Revista Chilena de Derecho, 2001, pp. 201-214.

${ }^{14}$ Cfr. Rosario Guzmán E., Mi hermano Jaime, 1991, pp. 97-98. 
pueda dejar sin justificar intelectualmente, y usa razonamientos filosóficos (a menudo incompletos) más que prudenciales para argumentar la validez de sus opciones. Este hecho, unido a su tremenda capacidad de convencimiento y razonamiento lógico, acaba siendo su perdición (en lo académico). Guzmán necesita que cualquier acción o decisión le encaje intelectualmente, que todas las ideas formen un cuerpo orgánico y trascendental, razonado y fundamentado. En esto sí que puede considerarse como un pensador y no un político.

Buscar el hilo argumental filosófico de los planteamientos Guzmán resulta, de este modo, muy seductor e incluso obligado, ya que era él mismo quien se empeñaba en encontrarlo, y conseguía que todo encajara bastante bien. De alguna manera puede decirse que Guzmán va topándose con ideologías que se ensamblan mejor que las anteriores para justificar racionalmente su posición política y defender la libertad económica. Las va utilizando sin ruptura entre una y otra.

Veamos cómo: Cristi demuestra cómo Guzmán, desde la visión corporativista del primer momento, prima los derechos individuales respecto a la sociedad fundado en su prioridad ontológica, sin reparar, como ya señalamos, en el carácter de "accidente necesario" de ésta que define Santo Tomás. De este modo otorga a su corporativismo un corte individualista, que en los 70 podrá defender igualmente de la mano del neoliberalismo. Al mismo tiempo, la defensa de la autoridad del nacionalismo clásico puede llegar a identificarse con la autoridad que se necesita para defender la libertad del individualismo liberal frente al Estado. Al descubrir a Hayek, Guzmán repara en que la preeminencia de la individualidad privada sobre el Estado que defiende el liberal se articula casi a la perfección con sus primeras ideas gremialistas, pero en clave moderna y económica. Sin mayor dificultad recurre al principio de subsidiariedad de la tradición corporativista para tintar a este liberalismo económico de "conservador", o casarlo con las ideas nacionalistas de la Junta, y las suyas propias. La elasticidad práctica del principio de subsidiariedad (capaz de "fluctuar" en función de lo que interese resolver) le viene que ni pintado para hilar el corporativismo primero con el neoliberalismo de después, y barnizar la última opción como católica.

Con todo esto pretendemos decir que Guzmán utilizaba argumentos de uno u otro signo en función de una conveniencia específica, porque creía en su validez, que intentaba demostrar. Su carácter excesivamente racionalista, necesitaba hallar causas racionales a cualquier 


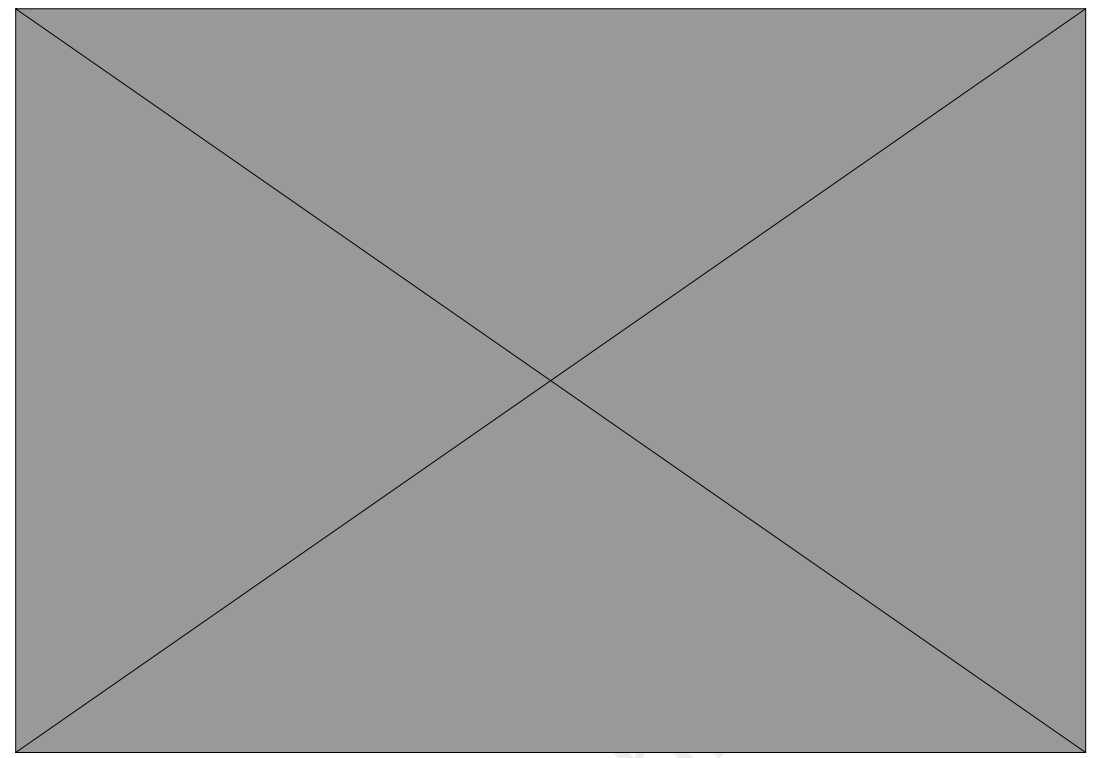

acción, y por ello es difícil definirle como "político" al uso. El político ha de justificar filosóficamente (fundamentalmente ante sí mismo) cualquier cambio, modificación o adscripción de rumbo político. Por su modo de ser, necesita que todo responda a un sistema de ideas, que nada sea un verso suelto. En todo momento su concepto de hombre, de sociedad, de economía, de familia, de trabajo, etc., ha de encajar mediante argumentos sólidos y profundos. Por este motivo se ve en la necesidad de hacer malabarismos con las distintas corrientes filosóficopolíticas sin que nadie se lo pidiera. De este modo, cuando se detecta una "falla" argumental en su sistema, da vueltas y revueltas hasta que consigue encajarlo, en un aparataje ideológico cada vez más complejo y discordante (unión del gremialismo con el liberalismo económico, subsidiariedad estatal y neoliberalismo, cristianismo con violación de derechos humanos, defensa del gremialismo con finalización de los colegios profesionales, etc.).

Sólo una mirada profunda como la de Cristi puede encontrar las contradicciones que encierra este juego racionalista de Guzmán. Un buen ejemplo de ello lo encontramos en la página 30 :

Durante la grave recesión de 1982, Guzmán percibe la necesidad de armonizar esos valores con los valores republicanos defendidos por la tradición conservadora chilena. Pero esa 
armonización resulta ser un proyecto sin destino. El haber puesto fuera de juego al corporativismo significa que las asociaciones intermedias que éste proponía y su espiritu solidario no son ya una alternativa viable. Sin esa base institucional, su replanteamiento republicano reaparece como un mero artificio retórico ${ }^{15}$.

A la vista de lo anterior, nos gustaría matizar la opinión de Cristi en un punto: en la evolución del pensamiento de Guzmán no hay unidad conceptual ni síntesis. Hay prudencia, conveniencia y necesidad personal de racionalización.

\section{La importancia de la intención}

Podríamos decir que la característica más destacable del pensamiento político de Guzmán reside en la combinación que hace de valores filosóficos, oportunismo político y oratoria, en su afán por otorgar practicidad a sus planteamientos. Por eso cabe el peligro de tachar a Guzmán de político "vacío". El libro de Cristi viene a demostrar lo contrario.

Es cierto que la intención de Guzmán no era dotar a Chile una nueva teoría política, sino sintetizar la que ya existía y consideraba buena para adecuarla a la realidad del país. Conviene ser consciente de ello a la hora de estudiar el pensamiento del político chileno. Enfatizar la opinión de Guzmán respecto al liberalismo económico, corporativismo u otros temas es quizá arriesgado, ya que Guzmán, como demuestra Cristi, no es un teórico sistemático. Si por algo se caracteriza el político es por la insistencia en la practicidad, en la posibilidad de realización. La adopción de políticas o medidas en función de estos planteamientos obliga a que su justificación teórica lleve consigo de manera inevitable ciertas contradicciones. Desde este punto de vista se entiende bien que Cristi encuentre ambigüedades en el pensamiento de Guzmán. Dichas contradicciones existen, sin duda, y Cristi las señala con enorme precisión. La incompatibilidad del concepto guzmaniano de bien común con la noción liberal de individuo, el valor relativo que confiere a los derechos humanos en aras al bien común al lado del valor absoluto del de-

${ }^{15}$ Renato Cristi, El pensamiento politico de Jaime Guzmán..., 2011, p. 30 (las cursivas son nuestras). 
recho de propiedad, la adscripción a la teoría económica neoliberal sin dejar de prescindir de la justicia social, etc. Hay, sin duda, numerosos términos que no resisten un análisis filosófico serio, que es lo que viene a demostrar este estudio de Cristi.

En este sentido, la unidad de distintas corrientes y tradiciones políticas chilenas conseguidas por el gremialista de la que habla Cristi, constituye una afirmación arriesgada. No puede decirse que Guzmán sostuviera postulados corporativistas en un principio, de los cuales sólo pudo aplicar parte. Más bien el corporativismo, así como la economía neoliberal, o la democracia orgánica, fueron utilizados por Guzmán en la medida en que los juzgó aplicables. Su intención no era darle a Chile una nueva teoría política, sino utilizar lo que había y convenía para adecuarlo a la realidad del país. Quizá sea más conveniente hablar, más que de síntesis, de puesta a prueba de distintos conceptos teóricos, hasta dar con los más cómodos u oportunos en una arena política determinada, en una circunstancia histórica concreta.

El enorme instinto político de Guzmán logra fundamentar sus razonamientos mezclando argumentos jurídicos, filosóficos, políticos, sociológicos o morales en función de lo que mejor calce en cada momento para defender una idea que él considera políticamente relevante y "practicable". Como señalamos en su día ${ }^{16}$ es, en definitiva, esta conveniencia la que otorga a todos sus planteamientos una intencionalidad exclusivamente política. De ahí nuestra cansina intención de dejar claro que los planteamientos políticos de Guzmán se deben más a las circunstancias que a las abstracciones políticas.

Renato Cristi ha hecho un trabajo académico riguroso de examen del pensamiento de Guzmán. Ha rastreado las corrientes filosóficas y políticas de las que bebe su filosofía, hasta elaborar un cuadro exacto de su genealogía ideológica. Y las conclusiones son deslumbrantes y acertadísimas. En este sentido hay que reconocer el mérito de Cristi al encuadrar el pensamiento de Guzmán del bagaje filosófico que le corresponde, del cual, en algunos casos, quizá ni el mismo Guzmán fuera consciente. p. 30 .

16 Renato Cristi, El pensamiento politico de Jaime Guzmán..., 2011, 


\section{BIBLIOGRAFÍA}

Comisión Constituyente. "Actas Oficiales de la Comisión Constituyente", Sesión 37, 2 de mayo de 1974, pp. 9 y 10.

Cristi, Renato. El pensamiento político de Jaime Guzmán: Una biografia intelectual. LOM Ediciones, 2011.

"La noción de Poder Constituyente en Carl Schmitt y la génesis de la Constitución chilena de 1980". Revista Chilena de Derecho, Vol. 20, 1993, pp. 229-250.

Guzmán, Jaime. "El capitalismo y los católicos de tercera posición”. Fiducia, año III, No 20 , octubre de 1965.

- "La Iglesia chilena y el debate político". Recogido por Arturo Fontaine Talavera en "El miedo y otros escritos: El pensamiento de Jaime Guzmán E.”. Estudios Públicos, No 42 (otoño 1991), p. 279.

"Bases esenciales de la institucionalidad chilena. Comentario en torno al Acta Constitucional $\mathrm{N}^{\mathrm{0}} 2$, promulgada el 11 de septiembre de 1976". Constitución y Legislación, 1977, 2, C162 JG, Santiago, Fundación Jaime Guzmán E.

Guzmán Errázuriz, Rosario. Mi hermano Jaime. Santiago, Editorial Ver, 1991, pp. 97-98.

Moncada Durruti, Belén, "Financiación de la cohesión social: Consideraciones e inquietudes". En Francisco Aldecoa Luzárraga (ed.), La cohesión social en Iberoamérica: III Jornadas Iberoamericanas de Estudios Internacionales. Marcial Pons Ediciones Jurídicas y Sociales 2008, pp. 365-370.

- Jaime Guzmán el político: Una democracia contrarrevolucionaria. Santiago: Ril Editores, 2006.

"Reseña al libro Cristi, Renato: El pensamiento político de Jaime Guzmán. Autoridad y Libertad, Santiago, LOM Ediciones, 2000”. En Revista Chilena de Derecho, 2001, Vol. 28 No 1, pp. 201-214.

Orrego Vicuña, Claudio. Cartas privadas: 1973-1977. Santiago: Editorial Aguilar, 2002.

Pérez Adán, José. "Pautas de evaluación para el desarrollo y la igualdad en América Latina". En XIII Congreso Iberoamericano Ciencia y Vida: Dignidad e Igualdad en América Latina, Universidad Santo Tomás, Santiago de Chile, 27, 28 y 29 de julio de 2007. 